\title{
Editorial: Number 49
}

\author{
Ken Coates
}

The Northern Review has always aspired to be a broad and inclusive academic journal, focusing on northern topics, contributions from northern residents, enthusiastically multidisciplinary, and open to new and provocative voices. Issue Number 49 continues in the well-established tradition.

This issue focuses on two important themes: the development of the often neglected Provincial North in Canada, and the evolution of place-based sustainability research. The latter theme reminds us of the contemporary challenge of moving beyond the rhetoric of empowering northerm communities, to doing the hard work of transforming the passion for locally controlled sustainability into practical and effective action.

The focus on the Provincial North in Canada, which has been an important analytical priority for the Northern Review for some time, draws attention to the divisions within the region. The Provincial North has ten times the population of the Territorial North, a more robust resource economy, and a wealthier population. It also has some of the poorest communities in Canada, serious infrastructure deficits, almost no political autonomy, and a great deal of control exercised by provincial governments. The Provincial North also attracts little attention from the Government of Canada.

Number 49 also includes a fascinating set of general articles. The Northern Review celebrates the diversity of research and analysis that is an integral part of the "new North." The papers in this section celebrate 
a variety of voices and perspectives, encouraging young scholars, nonacademics, practitioners, and others to contribute their ideas. Equally, the journal continues to celebrate different ways of knowing and sharing ideas.

One of the great strengths of the Northern Review is the breadth and range of the topics and ideas it presents. We invite readers to explore this issue with an open mind and a sense of intellectual curiosity. The Northterritorial, provincial, and circumpolar-is an important and fascinating place. Enjoy your exploration and your encounter with the diverse and fast-growing intellectual traditions here.

Ken Coates is professor and Canada Research Chair in Regional Innovation, Johnson Shoyama Graduate School of Public Policy, University of Saskatchewan; Fellow, Royal Society of Canada; and a founding and senior editor of the Northern Review. 